\title{
(Novas) fronteiras e ideários coloniais de longa duração: uma análise a partir da disputa pela reconfiguração territorial da Amazônia brasileira' ${ }^{1}$
}

\author{
(New) frontiers and long-term colonial images: \\ an analysis from the dispute by the territorial \\ reconfiguration of the Brazilian amazon
}

\section{Telma de Sousa Bemerguy}

Doutoranda do Programa de Pós-Graduação em Antropologia Social do Museu Nacional/UFRJ. ID ORCID: https://orcid.org/0000-0002-4864-0010.

\section{Resumo}

Em 2011 foi realizado um plebiscito no estado do Pará para consultar a população acerca do interesse em dividi-lo em três: Pará, Tapajós e Carajás. Tomando esse processo como ponto de partida, neste artigo farei algumas considerações sobre interesses políticos e econômicos de longo prazo envolvidos na disputa em torno da reconfiguração territorial da Amazônia Brasileira. Através da análise de relatórios técnicos e de debates realizados no Congresso Nacional no contexto da aprovação da realização do plebiscito pela criação dos estados de Tapajós e Carajás apresentarei uma etnografia voltada às ideias e significados particulares (re)produzidos através do exercício do poder estatal (GEERTZ, 1991), buscando demonstrar como uma determinada "imagem" de Amazônia (OLIVEIRA, 2008, 2016) - fruto de representações duráveis produzidas no marco de processos colonialistas de longa duração - foi acionada e agenciada politicamente ao longo da disputa pela reconfiguração territorial da região.

Palavras-chave: Novos Estados, Fronteiras Internas, Agronegócio, Colonialismo, Amazônia.

\section{Abstract}

In 2011, a plebiscite was held in the Brazilian state of Pará to consult the people about their opinion on dividing this federated state into three new ones: Pará, Carajás e Tapajós. Starting from this process, in this article, I will present some considerations about long-term political and economic interests involved in the dispute over the territorial reconfiguration of the Brazilian Amazon. Through the analysis of technical reports and of the debates held in the National Congress in the context of

As reflexões apresentadas neste artigo foram resultado de pesquisa de mestrado realizada entre 2014 e 2016, com financiamento de bolsa de estudos oferecida pela Coordenação de Aperfeiçoamento de Pessoal de Nível Superior (Capes). 
the approval of the plebiscite by the creation of the states of Tapajós and Carajás, I will present an ethnography focused on the particular ideas and meanings (re)produced through the exercise of state power (GEERTZ, 1991) to demonstrate how a particular image of the Amazon (OLIVEIRA, 2008,2016 ) - conformed through durable representations produced within the framework of longterm colonialist processes - was addressed and politically agencied throughout the dispute for the territorial reconfiguration of the region.

Keywords: New States, Internal Borders, Agrobusiness, Colonialism, Amazon.

\section{INTRODUÇÃO}

No processo de formação do Estado-Nação brasileiro, a configuração da relação entre as "partes" (províncias/regiões/estados/municípios) e o "todo" da nação foi marcada por diversos conflitos ligados a disputas por autonomia administrativa e anseios em torno de projetos de desintegração ou reconfiguração do território nacional (MATTOS, 1990; MARTINS, 2003; OLIVEN, 2006). A atual organização político-administrativa do Estado brasileiro é fruto de um longo processo histórico de negociações: um espelho das variações na conformação do campo das relações políticas e das disputas pelo poder nas diferentes "partes" do país. Apesar de ser este um debate recorrente em diversos momentos da história do Brasil, os acordos em torno da configuração político-administrativa do território nacional e questões de disputa a respeito dos limites territoriais internos do país constituem situações de pesquisa ainda pouco exploradas em etnografias interessadas em contribuir com análises sobre a processo de formação do Estado-nação brasileiro. Neste artigo tratarei de um dos capítulos mais atuais dessa disputa, abordando as ideias e interesses particulares que perpassaram a mais recente tentativa de redesenhar internamente o território nacional.

Em 2011 foi realizado um plebiscito no estado do Pará para consultar a população acerca do interesse em dividi-lo em três: Pará, Tapajós e Carajás. Os resultados mostraram $66,08 \%$ de votos contrários à criação do Tapajós e 66,60\% de votos contrários à criação do Carajás ${ }^{2}$. A iniciativa, no entanto,

\footnotetext{
Apesar dos projetos compartilharem um enredo com muitos pontos em comum, nos limites deste trabalho, as particularidades do processo de criação do estado do Carajás não serão aprofundadas. Para maiores informações sobre esse projeto em particular, ver Lisboa (2014). Em sua dissertação, a autora apresenta uma análise sobre as propagandas eleitorais favoráveis à criação do Estado do Carajás durante a campanha realizada para o plebiscito.
} 
se tornou um marco jurídico importante na discussão sobre a organização político-administrativa do território, visto que esta foi a primeira vez que a população de um estado foi consultada a respeito da possibilidade de se criar uma nova unidade federativa no país. Tomando como ponto de partida os relatos de atores envolvidos na mobilização favorável à efetivação do estado do Tapajós, em minha pesquisa de mestrado (BEMERGUY, 2017) tive a intenção de construir uma etnografia sobre o processo de criação de uma unidade federativa, expondo as ações realizadas ao longo do tempo para possibilitar que esse novo estado fosse criado. Ao longo do trabalho, refleti sobre quais elaborações, provas, repertórios argumentativos e justificativas foram utilizados para produzir a crença de que a luta pela criação do estado do Tapajós era uma "causa"3 (BOLTANSKI, 1990) em nome do bem comum de uma "região" (BOURDIEU, 1989)4 particular.

Ao seguir o caso através dos inúmeros espaços e temporalidades narrados e percorridos por meus interlocutores, deparei-me com os desafios de abordar uma mobilização em torno de um projeto político necessariamente articulado em múltiplas escalas. Assim, vi os relatos sobre o universo cotidiano da luta por mobilizar apoio ao projeto nas cidades que conformariam o novo estado chegarem até os corredores de Brasília e à enorme gama de negociações conduzidas ao longo do tempo para possibilitar que o projeto de criação do Estado do Tapajós fosse pautado e aprovado nas inúmeras alas e comissões que compõem o Poder Legislativo. No texto irei compartilhar algumas das questões com que me deparei no decorrer dessa

\footnotetext{
Boltanski (1990) afirma que, para que um protesto possa vir a ser reconhecido e tratado como uma "causa", os atores que se sentiram injustiçados devem produzir uma denúncia pública admissível dessa injustiça. O autor sugere então que essas condições de admissibilidade estão relacionadas a um "conjunto de coações que se impõe a todos" e à necessidade de se utilizar uma gramática comum explorando as possibilidades de generalização da injustiça denunciada. Seguindo sua proposta, em meu trabalho apropriei-me da ideia de gramática para refletir sobre quais retóricas viabilizaram o trâmite do projeto de criação do novo estado até o plebiscito e sobre quais argumentos tiveram a força para conseguir agregar indivíduos com perfis e expectativas díspares em torno de um projeto comum, ou seja, quais linguagens foram mobilizadas para "fazer a causa crescer".

${ }_{4}$ Nos termos propostos por Bourdieu (1989), em minha dissertação (BEMERGUY, 2017) pretendi apresentar como a mobilização pela criação do estado do Tapajós podia ser lida como uma manifestação de "regionalismo". Nos limites deste trabalho essa discussão não será explorada.
} 
experiência de pesquisa, privilegiando a descrição das articulações realizadas "para cima", no contexto do Congresso Nacional.

Por meio da análise de relatórios técnicos e dos debates realizados na conjuntura de aprovação da realização do plebiscito, evidenciarei uma etnografia voltada às ideias e significados particulares (re)produzidos através do exercício do poder estatal (GEERTZ, 1991), no intuito de demonstrar como uma determinada "imagem" de Amazônia (OLIVEIRA, 2008, 2016) - fruto de representações duráveis elaboradas no marco de processos colonialistas de longa duração - foi acionada e atualizada ao longo da disputa pela reconfiguração territorial da região. Meu objetivo será demonstrar como as evidentes continuidades entre as representações mobilizadas nos discursos e materialidades produzidas para legitimar propostas de reconfiguração territorial da Amazônia ao longo do tempo podem ser um ponto de partida interessante para compreender como projetos desse porte alcançaram o apoio político que possibilitou a realização do plebiscito.

\section{ETNOGRAFANDO PROCESSOS DE ESTADO}

Antes de tudo, penso que seja importante apresentar algumas considerações sobre a forma como busquei abordar os processos estatais etnografados ao longo da pesquisa. Seguindo Abrams (1988), penso que "O Estado", como uma abstração reproduzida pela força da crença, é, antes de tudo, uma "ilusão bem fundamentada" de exterioridade e racionalidade, uma "ideia" difundida de que toda a existência desse "ente" teria como princípio e sempre seria voltada para o "interesse comum da sociedade". Abrams (1988) procura demonstrar que muitas das dificuldades em estudar "O Estado" são relacionadas ao fato de que, durante muito tempo, diversas abordagens analíticas delimitaram que se partisse da crença de que haveria um "Estado de fato",

5 A expressão cunhada por Nader (1972) se tornou uma forma corrente de referenciar trabalhos antropológicos sobre grupos ou sujeitos em posições hierárquicas superiores ou simétricas à do pesquisador e sobre grupos que ocupam a ponta de cima das relações de poder que regulam a vida das minorias usualmente estudadas pela antropologia, tais como os agentes de Estado e as elites econômicas. Para uma discussão sobre o lugar desse debate na produção antropológica brasileira, ver Castilho; Souza Lima; Teixeira (2017). 
escondido "por trás das práticas políticas". Para escapar da iminência de reificar "O Estado" quando este é tomado como objeto de reflexão, o autor propõe uma conceituação instrumental, a qual sintetiza em dois termos: "Estado-sistema" e o "Estado-ideia". O primeiro seria a dimensão do Estado como "prática e estrutura institucional", e o segundo, essa percepção particular de Estado "difundida e acreditada", com força para conduzir as expectativas sobre como esse Estado-prática deveria ser. Mitchel (2006), por sua vez, destaca que o processo de reprodução desse "Estado-ideia" depende grandemente do sucesso em "fazer crer" no caráter abstrato e impessoal do exercício do poder. Para produzir essa crença, denominada pelo autor de "efeito de Estado", são necessárias práticas, técnicas e materialidades que reafirmem cotidianamente a confiança nessa exterioridade e nesse "O Estado" que, em algum lugar, funciona perfeitamente gerido pela impessoalidade asséptica da burocracia.

Não são poucos os trabalhos que demonstram como abordagens etnográficas sobre os aspectos materiais e ideológicos que compõem a crença no "Estado enquanto um ente uno" e apartado das relações sociais são exercícios que permitem olhar por trás da "máscara" e descrever como "O Estado" se faz enquanto tal, cotidianamente, através de rituais, simbologias, representações, tecnologias de governo, de gestão, de administração e subjetivação (SOUZA LIMA, 2002a; SHARMA; GUPTA, 2006; CASTILHO; SOUZA LIMA; TEIXEIRA, 2014). Em diálogo com esse conjunto de trabalhos, parto da interpretação de que o Estado é, sobretudo, um "feixe de relações de poder" (CASTILHO; SOUZA LIMA; TEIXEIRA, 2014) e que, assim, deve ser analisado sempre como um "processo dinâmico e inconcluso" (SOUZA LIMA, 2012), na qualidade de uma "cosmologia que é apropriada e redimensionada segundo histórias socioculturais específicas" (SOUZA LIMA, 2002b, p 265). Um "fazer" cotidiano de formas de dominação que, conforme destaca Souza Lima (2002b), mobiliza símbolos, saberes e modos de transmissão de saberes que possuem profundidade histórica e uma genealogia que, no caso brasileiro, remonta aos processos de colonização. Penso que os contornos dessa durabilidade podem ser examinados de maneira particular ao analisarmos os sujeitos e os discursos involucrados em projetos estatais pensados para a Amazônia. A análise de propostas de reconfiguração territorial da região, na medida em que mobilizavam anseios em torno de um Estado tal "como de- 
veria ser", me permitiu acessar elaborações transparentes sobre o que se entendia por "Amazônia" e sobre o "Estado" que se queria "presente" na região.

Tal como Oliveira $(2008,2016)$, partilho da leitura de que a "Amazônia" é, antes de tudo, uma "imagem" com capacidade de dirigir perguntas e ações e, muitas vezes, de governar expectativas e emoções. Essa ideia tem me parecido interessante para refletir sobre as práticas de governo destinadas à região. Nesse sentido, penso que incide sobre esse território um "conjunto de generalizações históricas" persistentes que atuam a serviço da manutenção das fronteiras de uma "geografia imaginativa", que segue "inventando" (SAID, 1990) esse espaço como um "imenso vazio", como uma "terra sem homens", um "paraíso perdido", um "inferno verde", o "celeiro do mundo", a "última fronteira” (VELHO, 2009; OLIVEIRA, 2016), um lócus da barbárie à espera de integração e civilização.

Em diálogo com os trabalhos apresentados até aqui, ressalto que a própria etnografia sobre o "como fazer" do processo de criação de uma nova unidade federativa compõe uma reflexão sobre a prática política em si, uma espécie de escrutínio das "regras do jogo" em torno da disputa pela criação do estado do Tapajós. A partir desta proposta, pretendo tensionar a "máscara" (ABRAMS, 1988) do "efeito de Estado" (MITCHEL, 2006), apontando as técnicas e materialidades mobilizadas para "fazer o processo andar" e o universo simbólico que a ação política (GEERTZ, 1991) concomitantemente conforma e agencia em torno da "Amazônia".

\section{COMO SE CRIA UM ESTADO: O PASSO A PASSO DA TRAMITAÇÃO}

A criação de uma nova unidade federativa não é algo simples de se articular. É importante manter em mente que tratamos aqui de um projeto cujo objetivo é redesenhar os limites internos do país. Por isso, se em determinada escala a proposta era produzida por meus interlocutores como uma "luta de

\footnotetext{
6 Em alguns pontos do texto utilizarei aspas quando me referir a Amazônia, para destacar que o termo não é somente menção a uma localização geográfica, mas também uma referência às imagens e invenções que recaem sobre essa região.
} 
um movimento social" ou como um "sonho de uma região", em outra este se tornava uma matéria de "relevância nacional", "de competência da União"7 - "codificado" como um debate e uma disputa sobre a forma da "organização político-administrativa"8 do Estado brasileiro. Trata-se, portanto, de uma questão fortemente regulamentada que, como tal, deveria cumprir um longo processo de trâmite para ser aprovada.

A criação de novas unidades federativas no país está prevista na Constituição Federal (CF) de 1988. No parágrafo $3^{\circ}$ do artigo 18 da CF está indicado que "os Estados podem incorporar-se entre si, subdividir-se ou desmembrar-se para se anexarem a outros, ou formarem novos Estados ou Territórios Federais", mas as propostas de reconfiguração territorial estariam sujeitas à “aprovação da população diretamente interessada”, a qual deveria ser consultada através de plebiscito. Ainda conforme a CF, no caso de uma resposta positiva na consulta, o projeto também precisaria ser aprovado pelos parlamentares no Congresso Nacional, onde uma lei complementar, criando formalmente a nova unidade federativa, deveria ser sugerida e debatida. Sua aprovação estaria sujeita ao cumprimento de alguns requisitos.

Esse último passo, na verdade, representaria uma nova apreciação do projeto pelos parlamentares, pois a própria convocação de plebiscitos é um ato de competência exclusiva do Congresso Nacional (art. 49º XV, CF/1988), sendo este um dos caminhos previstos na Constituição para o exercício da soberania popular (art.14, $\mathrm{CF} / 1988$ ). No caso de plebiscitos sobre a criação de novos estados há uma regulamentação específica definida pela Lei Complementar n 9.709/1998, a qual estabelece orientações para o trâmite do processo. Ali estava previsto que plebiscitos sobre incorporação, subdivisão ou desmembramento de estados deveriam ser convocados mediante projeto de decreto legislativo e que, por ser esta uma “questão de relevância nacional”, só poderia ser proposta se ratificada por no mínimo um terço dos membros que compõem quaisquer das Casas do Congresso Nacional (Lei nº 9.709/1998, art. $\left.3^{\circ}\right)$.

\footnotetext{
No Regimento Interno do Senado Federal, na parte em que se delimitam as competências da Comissão de Constituição, Justiça e Cidadania, está previsto, no art 101\% , inciso II, que cabe a esta "emitir parecer, quando ao mérito, sobre as matérias de competência da União, especialmente as seguinte: a) criação de Estado e Territórios, incorporação ou desmembramento de áreas a eles pertencentes;" (BRASIL, 1970)

8 No arquivo disponível no bando de dados do Senado Federal sobre o substitutivo do projeto de decreto legislativo n¹9/1999 que convoca o plebiscito sobre a criação do estado do Tapajós está indicado, no item assunto: "Administrativo - Organização Político-Administrativa do Estado".
} 
A regulamentação estabelece também que, no caso de um resultado favorável, o projeto de lei complementar exigido para criar formalmente uma nova unidade federativa poderia ser proposto em qualquer uma das Casas do Congresso, à qual caberia conduzir audiências junto à respectiva Assembleia Legislativa da unidade que se debate redesenhar. As Assembleias, por sua vez, deveriam opinar sem "caráter vinculativo à matéria", e a elas caberia "fornecer o detalhamento técnico concernente aos aspectos administrativos, financeiros, sociais e econômicos da área geopolítica afetada" (conforme a Lei no 9.709/1998, art. $4^{\circ}$, parágrafo $3^{\circ}$ ) (BRASIL, 1998). A apreciação final da matéria pelos parlamentares deveria ser realizada a partir desse detalhamento técnico.

Em linhas gerais, a partir do dispositivo jurídico previsto na CF/1988 e da legislação complementar citada, o caminho necessário para se criar um novo estado passou a ser: 1) proposição de um projeto de decreto legislativo convocando o plebiscito sobre a matéria; 2) encaminhamento da matéria à Comissão de Constituição, Justiça e Cidadania'; 3) ratificação do projeto por no mínimo um terço dos membros de qualquer Casa do Congresso; 4) elaboração de um parecer favorável pelo relator escolhido; 5) aprovação do projeto em sessão deliberativa no Senado Federal e na Câmara dos Deputados; 6) realização do plebiscito; 7) resposta favorável ao projeto no plebiscito; 8) proposição de lei complementar para criação do novo estado; 9) realização de audiências com a Assembleia Legislativa do estado que será redesenhado; 10) apresentação de estudos técnicos que indiquem a viabilidade ou não do projeto; 11) provar a viabilidade; 12) aprovação em ambas as Casas de Lei Complementar, criando o novo estado; 13) sanção da lei pelo Presidente da República.

Assim, no dia 2 de março de 1999, o Senador Mozarildo Cavalcanti, naquele momento representante eleito pelo estado de Roraima, protocolou no Senado Federal o projeto de decreto legislativo (PDS) que originou o processo que levou à realização do plebiscito. Por aproximadamente dois anos e sete meses o projeto foi avaliado, revisado e retificado, até chegar à redação final,

\footnotetext{
9 Segundo o Regimento Interno do Senado, também era esperado que a Comissão de Constituição, Justiça e Cidadania pudesse "emitir parecer, quanto ao mérito, sobre as matérias de competência da União", dentre elas, a) criação de Estado e Territórios, incorporação ou desmembramento de áreas a eles pertencentes (art.101, parágrafo II, Regimento interno do Senado) (BRASIL, 1970).
} 
no dia 24 de outubro de 2001. Dez anos depois, no dia 11 de maio de 2011, a Câmara dos Deputados, através de articulações realizadas pelo Deputado Federal Lira $\mathrm{Maia}^{10}$, Conforme informações disponibilizadas na página do Senado Federal, quando são sugeridas mudanças a uma proposta legislativa que a alterem integralmente, o novo texto ganha o nome de substitutivo e precisa ser votado novamente. No caso do PDS 19/1999, o substitutivo ${ }^{11}$ apresentado teve como objetivo incluir a menção a municípios criados posteriormente a apresentação do PDS no texto de descrição da área a ser desmembrada para a criação do novo Estado. Este último percorre um caminho bem mais rápido e é aprovado em caráter de urgência vinte dias depois, no dia 31 de maio de 2011.

Para conseguir criar uma nova unidade federativa era necessário haver a aprovação de um projeto de decreto legislativo no Congresso Nacional para provocar a realização de uma consulta plebiscitária "na área diretamente interessada", produzir "provas" que sustentassem a viabilidade econômica da nova unidade federativa e mobilizar ações e justificações que garantissem apoios tanto entre o meio político-partidário quanto entre a população da região. O projeto precisava agregar uma enorme força política para se concretizar. Assim, nessa escala da luta, a partir da Constituição de 1988, o principal objetivo dos militantes pela criação pelo estado do Tapajós ${ }^{12}$ passou a ser

${ }^{10} \mathrm{O}$ trabalho realizado por Lira Maia para aprovar a pauta foi divulgado nos canais de vídeo de seu partido, Imprensa Democratas. Disponível em: https://www.youtube.com/watch?v=SxWe2OhhEDg. Acesso em: 01 jan. 2017.

${ }^{11}$ Conforme informações disponibilizadas na página do Senado Federal, quando são sugeridas mudanças a uma proposta legislativa que a alterem integralmente, o novo texto ganha o nome de substitutivo e precisa ser votado novamente. No caso do PDS 19/1999, o substitutivo apresentado teve como objetivo incluir a menção a municípios criados posteriormente a apresentação do PDS no texto de descrição da área a ser desmembrada para a criação do novo Estado. Fonte: AGÊNCIA SENADO. Substitutivo. Disponível em: https://www12.senado.leg.br/noticias/glossario-legislativo/substitutivo. Acesso em: 27 ago. 2019.

${ }^{12}$ A primeira instituição com o objetivo de lutar pela criação do estado do Tapajós surgiu informalmente em 1985, e passou a ter personalidade jurídica em 1991, nomeada de "Comitê Pró-Criação do Estado do Tapajós". Desde então o coletivo organizado para lutar pelo projeto teve inúmeros desdobramentos, fragmentando-se em mais de uma instituição (Frente Popular Pró-Emancipação do Estado do Tapajós; Fórum Permanente pela Criação do Estado do Tapajós) e daí unindo-se novamente em 2004 (Movimento pelo Plebiscito e pela Criação do Estado do Tapajós) para, por fim, ser renomeado como "Instituto Cidadão Pró-Estado do Tapajós” (ICPET), em 2011. Entidade com personalidade jurídica sediada em sala cedida no prédio da Câmara dos Vereadores de Santarém, hoje é a única instituição a responder 
"fazer aprovar" um projeto de decreto legislativo que convocasse a realização do plebiscito. Para tanto, era necessário persuadir os parlamentares a apoiar a iniciativa, ir de gabinete em gabinete, desenvolver argumentos e, especialmente, comprovar a viabilidade econômica do novo estado, requisito constitucional para o encaminhamento da proposta. Ao longo desse processo, inúmeros históricos, estudos, pareceres e relatórios foram produzidos, a fim de sustentar a legitimidade da ideia e embasar o debate e os pronunciamentos realizados por parlamentares que defendiam a "causa". Conhecer os principais aliados da luta no Congresso e a natureza dos argumentos apresentados em discursos e documentos produzidos nesse contexto é fundamental para compreender como se costuraram as alianças que possibilitaram a aprovação do projeto e a realização do plebiscito.

\section{PROVAS, ALIANÇAS E MATERIALIDADES: O TAPAJÓS INTERESSA AO BRASIL?}

Tomando como ponto de partida o ponto de vista dos parlamentares sobre sua própria atuação política, Bezerra (1999) demonstra que durante o exercício de seus mandatos, deputados e senadores consideravam que, para além de suas atribuições formais definidas pelos regimentos das Casas a que se ligavam, parte fundamental de seu "dever parlamentar" consistia em atender pedidos de suas "bases eleitorais". Observando especialmente as práticas de parlamentares para a liberação de recursos federais, Bezerra (1999) demonstra que essas concepções sobre suas atribuições os levavam a dar maior atenção às relações com os estados e municípios pelos quais haviam sido eleitos. Conforme procurei demonstrar na última seção, os procedimentos burocráticos indispensáveis para "fazer aprovar" um projeto de decreto legislativo com vistas a provocar a criação de uma nova unidade federativa estabeleciam a necessidade de conquistar apoio entre políticos de todos os estados da Federação, ou seja, entre representantes políticos que não possuíam suas "bases eleitorais" na área a que se destinava o projeto. Desse modo, também era ne-

pelo movimento para a criação do estado do Tapajós e que permanece em atividade. Neste artigo irei me deter apenas à dimensão da articulação do projeto conduzida no contexto do Congresso Nacional. Para mais informações sobre a mobilização realizada na região referente ao novo estado, ver Dutra (1999) e Bemerguy (2017). 
cessário apresentar argumentos sobre por que apoiar o projeto de criação do estado do Tapajós seria bom para o Brasil, para os grupos que compunham as "bases" ou para a carreira política dos parlamentares acionados.

Nesse quadro, um fato chamou minha atenção. Mozarildo Cavalcanti, autor do PDS 19/1999 que, ao final, provocou o plebiscito, não era um parlamentar eleito pelo Pará. Ele exerceu quatro mandatos ao longo de sua vida pública, dois como deputado federal (1983-1987/Partido Democrático Social; 1987-1991/Partido da Frente Liberal) e dois como senador (1999-2007/Partido da Frente Liberal; 2007-2015/Partido Trabalhista Brasileiro), todos como representante do estado de Roraima. Uma consulta ao resumo de sua atividade legislativa indicou-me caminhos para pensar sobre as razões que teriam motivado tal proposição. O caráter dos projetos apresentados durante sua vida parlamentar deixava claro o alinhamento com os interesses da bancada ruralista $^{13}$, ponto que se repetia na trajetória de outro importante personagem político ligado a essa articulação da temática: o deputado federal Lira Maia ${ }^{14}$. Referenciado como um "representante" da luta e indicado pelos militantes que entrevistei como "o" político a quem eu deveria procurar para falar sobre a questão, ao longo de sua vida pública, Maia exerceu cinco mandatos pelo estado do Pará: um como deputado estadual (1995-1996/Partido da Frente Liberal), dois para atuar como prefeito da cidade de Santarém (1997-2000; 2001-2004/ Partido da Frente Liberal) e dois como deputado federal (20072011/Partido da Frente Liberal; 2011-2015/ Democratas). Diferentemente de Mozarildo, seu excelente histórico de votos na região que seria desmembrada para a criação do Tapajós compunha um quadro perfeito para que muito possivelmente se tornasse o primeiro governador eleito do novo estado.

\footnotetext{
${ }_{13}$ O senador era um ferrenho opositor aos processos de demarcação de terras indígenas em Roraima. Seu nome era conhecido no debate sobre os direitos indígenas por ser de sua autoria uma das propostas de emenda constitucional (PEC 038/1999) que tem como objetivo transferir ao Senado Federal a competência de aprovar o processo de demarcação de terras indígenas. Dados sobre sua trajetória estão disponíveis no trabalho de Costa (2012), em seu perfil na página do Senado e em um verbete biográfico do acervo da Fundação Getúlio Vargas.

Fonte: SENADO FEDERAL (Brasil). Mozarildo Cavalcanti - RR. In: SENADO FEDERAL (Brasil). Senadores. [Brasília, DF]: Senado Federal, [2015]. Disponível em: https://www25.senado.leg.br/web/ senadores/senador/-/perfil/952. Acesso em: 12 dez. 2016.

FRANCISCO Mozarildo de Melo Cavalcanti. In: DICIONÁRIO Histórico-Biográfico Brasileiro. Rio de Janeiro: FGV, [2009]. Disponível em: http://www.fgv.br/cpdoc/acervo/dicionarios/verbete-biografico/ francisco-mozarildo-de-melo-cavalcanti. Acesso em: 12 dez. 2016.

${ }^{14}$ Costa (2012) apresenta um quadro detalhado sobre ação de deputados e senadores que compõem a bancada ruralista no Congresso Nacional, dentre eles, o Deputado Lira Maia.
} 
Entretanto, para além das diferenças observadas no envolvimento desses dois personagens no processo que levou à realização do plebiscito em 2011 e nas possibilidades que cada um tinha de fortalecer suas bases de voto através do projeto, é justamente o ponto em comum na trajetória política de Cavalcanti e Maia que viabiliza a compreensão de como os dois parlamentares acabaram juntos na luta pela criação do estado do Tapajós: a proximidade com a bancada ruralista. A centralidade dessa informação fica em evidência quando observamos de que maneira argumentos em torno da viabilidade econômica do projeto eram empregados para convencer interlocutores de que "criar o Tapajós seria bom para o Brasil". Desde o primeiro relatório publicado para corroborar a proposta, o principal caminho utilizado para afirmar que o novo estado poderia gerar a receita necessária para se manter de maneira autônoma foi colocar em destaque as potencialidades do projeto de asfaltamento da rodovia BR-163 (Santarém-Cuiabá), a qual cortaria grande parte do Tapajós, caso o estado fosse criado.

Figura 01 - Estado do Tapajós e a Rodovia BR-163

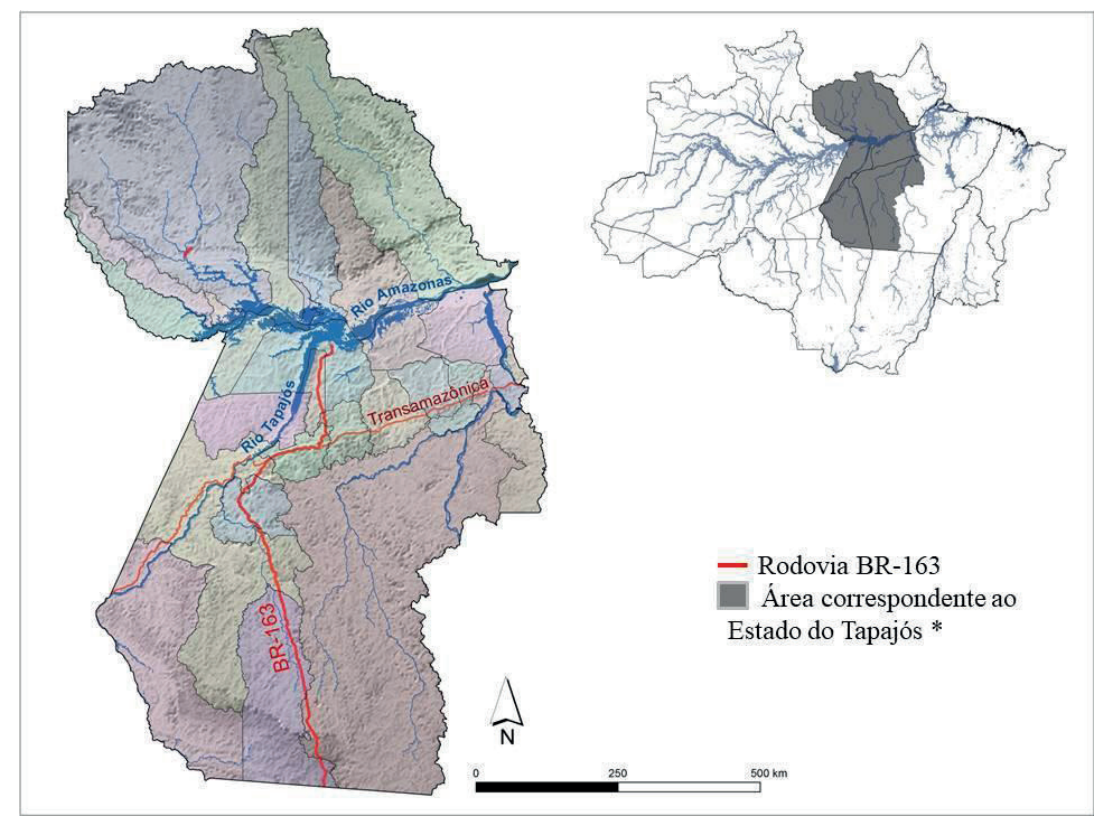

Fonte: Autor, 2017.

Elaborado por Maurício Torres (2017).

* Área referente ao projeto que deu base ao plebiscito em 2011. 
Inaugurada em 1973, a rodovia Santarém-Cuiabá é um dos resultados das políticas de integração nacional (PIN) promovidas pela Ditadura civil militar. A estrada atravessa 71 municípios, possui uma área de influência de 1.231,8 milhão de $\mathrm{km}^{2}$ e liga o município de Cuiabá, no Mato Grosso, ao município de Santarém, no Pará (TORRES, 2005). A via é considerada estratégica porque poderia possibilitar uma diminuição dos gastos com a distribuição de grãos produzidos no centro-oeste, facilitando seu escoamento para o mercado internacional através do uso de um porto mais próximo aos locais de produção, em Santarém e Itaituba, no Pará (ALARCON; GUERRERO; TORRES, 2016) ${ }^{15}$. Em função das condições de trafegabilidade da rodovia, que ainda hoje possui diversos trechos sem pavimentação dentro do estado do Pará, até então o eixo logístico majoritariamente utilizado para o escoamento da soja e outras commodities produzidas na região centro-oeste passava pelos portos de Santos, em São Paulo, e Paranaguá, no Paraná, um trajeto avaliado como mais longo e dispendioso. Conforme demonstram Alarcon, Guerrero e Torres (2016), a estruturação efetiva dessa "saída mais lucrativa pelo Norte" é uma expectativa antiga de setores do agronegócio nacional. Por isso, o asfaltamento da rodovia Santarém-Cuiabá, "a rodovia da soja”, tem sido uma pauta recorrente entre os produtores. Através do debate pela criação do estado do Tapajós, os interesses em torno da rodovia voltaram a ganhar destaque na ordem do dia do Congresso.

\section{SOBRE MARCOS E IDEIAS ATRAVÉS DO TEMPO: A ASSEMBLEIA NACIONAL CONSTITUINTE}

Por meu interesse em observar continuidades entre representações utilizadas para legitimar o projeto ao longo do tempo, cabe retornar a um evento

\footnotetext{
${ }^{15} \mathrm{O}$ destaque ao grande interesse de setores do agronegócio no projeto de asfaltamento da rodovia é fundamental para entender o quadro da controvérsia que se desenha em torno da disputa pela criação dos novos estados no Pará, contudo, nos limites deste artigo não será desenvolvida uma análise mais aprofundada acerca do lugar estratégico ocupado pela rodovia BR 163 na ampliação e consolidação da frente de expansão agrícola na região. Além dos trabalhos citados ao longo do texto, há uma vasta bibliografia disponível que trata sobre essa questão em particular, fundamental para que eu dimensionasse a amplitude do debate. Ver: Torres (2005); Castro, E. (2008); Castro, M.C.A. (2008); Bernardes e Freire Filho, 2010.
} 
anterior, considerado um marco, tanto pelos parlamentares aliados quanto pelos militantes ligados ao movimento pela criação do estado do Tapajós: a Assembleia Nacional Constituinte. Naquele momento, deputados da região do Tapajós (Paulo Roberto Matos, natural de Santarém; Gabriel Guerreiro, natural de Oriximiná; e Benedicto Monteiro de Alenquer) tentaram articular a criação do estado. Apesar do insucesso, a introdução de um artigo específico no Ato das Disposições Transitórias da Constituição prevendo a criação de uma Comissão de Estudos Territoriais, cuja finalidade seria "apresentar estudos sobre o território nacional e anteprojetos relativos a novas unidades territoriais, notadamente na Amazônia Legal e em áreas pendentes de solução" (BRASIL, [1990, p.50]), foi entendida por integrantes do movimento como resultado da articulação feita pelos deputados (DUTRA, 1999; BEMERGUY, 2017). No marco da CF/1988, esse foi o primeiro relatório técnico publicado sobre a proposta, o qual seria referenciado exaustivamente ao longo da tramitação do PL 19/1999, sendo retomado nos debates e incluído como anexo em inúmeros pareceres e relatórios produzidos para sustentar o percurso burocrático do projeto.

O relatório não era extenso, possuindo ao todo 25 páginas, entre o texto e os anexos. O texto em si era composto por duas partes. Primeiro, havia uma breve introdução apresentando as razões que levaram à criação da Comissão, quem eram seus integrantes e como os trabalhos haviam sido conduzidos. Em seguida havia uma seção denominada "Redivisão da Amazônia - justificativas e critérios”, na qual, em subtópicos separados, a Comissão avaliava cada um dos projetos de criação de novos estados ou territórios federais solicitados, indicando se estes cumpriam ou não critérios estabelecidos. $\mathrm{O}$ estado do Tapajós foi uma das propostas apreciadas ${ }^{16}$. Cada uma daquelas que recebeu parecer favorável do relator possuía um arquivo correspondente anexado: o seu anteprojeto, o qual era composto por um esboço do projeto de decreto legislativo que o processo de criação de uma unidade federativa demandava, e por uma seção denominada "justificação", em que os argumentos estavam postos de forma mais detalhada. No anteprojeto do estado do Tapa-

\footnotetext{
${ }^{16}$ Nos limites deste trabalho não me estenderei aos projetos avaliados, mas estes versavam sobre a criação do Território Federal do Rio Negro e do Território Federal do Alto Solimões, no estado do Amazonas, bem como do Território Federal do Araguaia, no estado do Mato Grosso. Por último, tratava da concepção do estado do Triângulo, a partir do desmembramento de 74 municípios do estado de Minas Gerais.
} 
jós, a Comissão destacou o grande potencial econômico da região e buscou justificar a proposta chamando a atenção para o que faltava. Nesse contexto, é mencionada a importância estratégica da rodovia Santarém-Cuiabá e de outras obras de infraestrutura.

Faltam ao Tapajós programas específicos de desenvolvimento de seus inegáveis recursos: embora o potencial hidrelétrico da área seja dos maiores da Amazônia, ainda é séria a carência energética. Faltam ao Tapajós pesquisas adequadas para orientar o aproveitamento de suas pujanças minerais. Falta-lhe infraestrutura para integrá-lo ao Sul e Sudeste do País através do Centro-Oeste e permitir o seu desenvolvimento portuário como canal alternativo para exportação e importação. A importância estratégica da rodovia que liga Santarém a Cuiabá para o desenvolvimento regional, é inegável, como é evidente o estado calamitoso da dita rodovia e que hoje sua recuperação não está entre as principais prioridades do Estado do Pará. É inadmissível que numa região dominada pelo transporte fluvial não existam instalações portuárias. Com exceção de Santarém e Óbidos, os portos da região são antigos, limitados e inadequados. Tal situação, sem dúvida, tolhe o desenvolvimento, as relações comerciais, a própria vida das pessoas (BRASIL, [1990, p. 65-66]) (grifo meu).

Nos estudos de viabilidade publicados nos anos que se seguiram (1993, 1996, 1997, 2001, 2004, 2007, 2011) havia trechos praticamente idênticos aos do relatório produzido pela Comissão, de modo que não era difícil observar uma linha argumentativa comum ao longo dos documentos. Primeiro, apresentavam uma série de dados numéricos referentes ao quadro econômico da região para mostrar o que já havia de produção e de renda, caso o estado fosse criado naquele momento; em seguida, passavam a ressaltar as potencialidades, ou seja, a "natureza em estado bruto" que havia para ser explorada. Do destaque às potencialidades seguia-se às denúncias de como o "Estado" não investia na infraestrutura necessária para que a região pudesse se desenvolver: rodovias, portos e hidrelétricas.

Nos estudos mencionados, que sempre referenciavam um ao outro, a viabilidade do projeto era justificada a partir da evidenciação de três tendências no potencial econômico da região, deixando evidente a centralidade de dois setores: mineração e agropecuária. 
1) Ampliação da exploração mineral, organizada em grandes projetos

2) A perspectiva de interligação econômica com o estado do Mato Grosso para a formação de um corredor de grãos. 3) A expansão da fronteira agrícola que hoje se encontra no norte do Mato Grosso e que com a implantação da BR-163 tende a se expandir para o Tapajós (COIMBRA, 1997, p. 75).

Penso que, se analisarmos em conjunto as recorrentes menções a essa "saída mais lucrativa” pelo norte (ALARCON; GUERRERO; TORRES, 2016) e o perfil dos principais personagens da articulação política para a aprovação do plebiscito, é possível afirmar que, conforme destacou Dutra (1999), no enredo da disputa pela reconfiguração territorial do estado do Pará existem dois projetos que se sobrepõem: a luta pela criação do estado do Tapajós e a demanda pelo asfaltamento da rodovia Santarém-Cuiabá. A justaposição entre o projeto de criação do novo estado e os interesses em torno da rodovia está colocada desde o início das mobilizações em torno da proposta (DUTRA, 1999) que permaneceram atuais e produtivas no quadro das articulações que culminaram na realização do plebiscito (BEMERGUY, 2017). No pano de fundo do debate reside mais uma questão que parece não perder a atualidade: a ideia de que a "Amazônia” ainda não está plenamente "integrada” ao Brasil.

\section{DIVIDIR PARA INTEGRAR: O TAPAJÓS E OS “BANDEIRANTES DO FUTURO”}

No dia 23 de novembro de 2000, o projeto de decreto legislativo 19/1999 apresentado pelo Senador Mozarildo Cavalcanti é incluído na ordem do dia da sessão deliberativa ordinária do Senado Federal. O mérito da proposta havia sido aprovado alguns meses antes pela Comissão de Constituição, Justiça e Cidadania e agora precisava ser debatido e votado pelos senadores. Após a deliberação entre os presentes, ao final daquele dia, o projeto foi aprovado e encaminhado para a revisão pela Câmara dos Deputados. Demoraria ainda dez anos para que a proposta voltasse à ordem do dia. A discussão realizada pelos senadores nessa sessão, decisiva para os rumos do processo, ilustra bem como uma certa "imagem" da "Amazônia" era (re)produzida e mobilizada es- 
trategicamente para fazer crer na legitimidade das propostas de reconfiguração territorial da região. Penso que acionar essa Amazônia-imagem consistia em uma estratégia fundamental para convencer os parlamentares de que "o projeto de criação do Tapajós seria bom para o Brasil”.

Nesse sentido, destacam-se principalmente os discursos do Senador Roberto Freire e do Senador Jader Barbalho, os quais, naquele momento, foram protagonistas no debate, defendendo o voto favorável ao projeto. Naquele momento, Roberto Freire, ${ }^{17}$ que já havia atuado durante quatro legislaturas como deputado federal pelo estado de Pernambuco, estava exercendo seu primeiro e único mandato como senador e era líder da bancada do Partido Popular Socialista (PPS). Jader Barbalho, um dos personagens mais influentes da bancada paraense no Congresso Nacional, após um mandato como vereador, um como deputado estadual, dois como deputado federal e dois como governador pelo estado do Pará, desempenhava as funções de seu primeiro mandato como senador da República pelo Partido do Movimento Democrático Brasileiro (PMDB). Dono de um patrimônio milionário em imóveis rurais, a afinidade do senador paraense com os interesses do agronegócio na região é conhecida (COSTA, 2012). Sua importância no meio político desse estado o transformava em um voto importante a se conquistar. Sua manifestação sobre o mérito do projeto, sem dúvida, agregava imensa força política.

Após algumas manifestações sobre a pauta, o senhor Presidente Antônio Carlos Magalhães concede a palavra ao Senador Jader Barbalho:

\begin{abstract}
"Senhor Presidente, quero ressaltar a importância e a provocação deste debate e cumprimentar o Senador Mozarildo Cavalcanti, que, não sendo representante do Pará, mas tendo suas raízes no meu Estado, se preocupa, ao lado de propor a redivisão territorial de diversos pontos da Amazônia, com um pedaço do meu Estado" (BRASIL, 2000, p. 23060).

"Senhor Presidente, a luta daquela região como a luta do sul do Pará é a de qualquer região e de qualquer população do Brasil: acima de qualquer divisão, o que deseja são mais investimentos, é a maior presença do poder público" (BRASIL, 2000, p. 23060).
\end{abstract}

7 SENADO FEDERAL (Brasil). Roberto Freire - PE. In: SENADO FEDERAL (Brasil). Senadores. [Brasília, DF]: Senado Federal, [2003]. Disponível em: https://www25.senado.leg.br/web/senadores/senador/-/perfil/71. Acesso em: 07 jan. 2018. 
"Tenho a certeza de que a Casa toda haverá de acolher a propositura do Senador Mozarildo. Nós da representação do Estado achamos conveniente o plebiscito. Que o povo daquela região e o povo do Pará estabeleçam um amplo debate a respeito dessa separação, das consequências positivas e das eventuais dificuldades que possam ter com a separação. Mas o povo do meu Estado, o povo daquela região, tem o direito, neste momento, de fazer o plebiscito e manifestar-se democraticamente" (BRASIL, 2000, p. 23061).

"Permite-me V. Ex a um aparte, nobre Senador Jader Barbalho?" - indaga o Senador Roberto Freire. Após a aquiescência do colega, a palavra é concedida ao senador pernambucano.

"Senador Jader Barbalho, a discussão a respeito do Estado do Tapajós teve início, do ponto de vista institucional, na Assembleia Nacional Constituinte [...]. Houve um intenso debate que se perdeu por pouco" (BRASIL, 2000, p. 23061).

"Quando se discute problemas da ocupação da Amazônia - e isso é algo que tem a ver com a efetiva ocupação da Amazônia - devemos lembrar [...] que uma forma de ocupação é a institucional, com a criação de Tribunais de Justiça, de Assembleias Legislativas, do Poder Executivo, portanto, da presença efetiva do Estado para o pleno exercício de cidadania dos caboclos perdidos pela Amazônia brasileira" (BRASIL, 2000, p. 23061).

Em todos os momentos que isso foi feito [...] os novos Estados cresceram e os velhos não diminuíram, cresceram junto também [...] No caso da Amazônia, ganhamos todos, na perspectiva concreta de ocupação daquela imensa área [...]. O Tapajós tem grande capacidade de desenvolvimento. Dessa forma, ganharemos todos nós (BRASIL, 2000, p. 23061).

A Amazônia representa o futuro do mundo. Na Constituinte criamos uma Comissão Especial que, posteriormente, analisou todo um processo político e administrativo nacional, inclusive a questão do desmembramento de Estados. A Comissão Especial discutiu, de forma sistêmica e organizada, a criação de novos Estados brasileiros, com ocupação racional. Tapajós, não tenha dúvida, foi um dos primeiros a ser apontado como de total viabilidade [...]. Este país precisa começar a fazer o bandeirante contemporâneo e o do futuro. Tapajós é uma 
dessas praças, onde bandeirantes de todos os rincões fincarão suas bandeiras (BRASIL, 2000, p. 23061-23062).

Com a palavra, novamente, o Senador Jader Barbalho:

"De forma lúcida, V.Exª dá uma contribuição imensa sobre a discussão da ocupação da Amazônia” (BRASIL, 2000, p. 23062).

"Entendo que se amanhã, por decisão democrática do povo do meu Estado, patrocinada por esse plebiscito, constituirmos o Estado do Tapajós, a obrigação do Governo Federal, dentro que a linha que a Constituição estabelece de apoio ao desenvolvimento regional, é intervir na questão. Por que deixar que se estabeleça uma redivisão territorial? Por que isso é um problema nosso? A Amazônia, além dos discursos, quer recursos, quer investimentos e, como política de desenvolvimento regional, creio que a redivisão territorial na Amazônia, não só no meu Estado, deveria compor um projeto nacional de ocupação com investimentos financeiros efetivos para a região. Então teríamos o que V. Ex a disse: a ocupação ordenada e patrocinada por nós, brasileiros, como política do Governo do Brasil de ocupação racional daqueles espaços imensos" (BRASIL, 2000, p. 23062).

\section{SEGUINDO OS TERMOS DE UMA GESTÃO COLONIAL}

Inspirada no que destaca esse conjunto de autores e principalmente nas elaborações de Geertz (1991) sobre a forma particular como os balineses significavam o poder, penso que através da ação política é (re)produzida uma "constelação de ideias" culturalmente orientadas pelas especificidades do processo histórico que constituiu uma determinada sociedade. Nessa direção, em diálogo com críticas pós-coloniais, parto da perspectiva de que relações de poder constituídas em experiências e configurações coloniais, bem como as representações que as fundaram e fundamentaram ao longo do tempo, forjaram hierarquias históricas duráveis (entre territórios, raças e culturas) que permanecem estruturando relações de dominação e produzindo corpos e territórios subalternos no sistema-mundo contemporâneo (QUIJANO, 2000; MIGNOLO, 2007; ESCOBAR, 2003). Para aproximar essa discussão a 
reflexões feitas a partir do contexto brasileiro, dialogo especificamente com as contribuições de Souza Lima (2007), assumindo assim que análises sobre o processo de formação do Estado no Brasil não podem perder de vista o "legado colonial" que perpassa o exercício da administração pública no país.

Considerando a profundidade e as particularidades históricas que compõem o debate em torno da configuração político-administrativa do território nacional, penso que os processos de disputa em torno dos limites territoriais internos do país, especialmente os processos referentes à configuração da "Amazônia", constituem situações de pesquisa reveladoras de ideários persistentes em torno da gestão dessa região e de sua população. Nesse ponto é interessante retomar algumas categorias e linguagens recorrentes mobilizadas para justificar os projetos. Nos relatórios e debates descritos vimos como os argumentos favoráveis à iniciativa intercalavam representações hiperbólicas em torno de um território gigantesco, rico em "natureza bruta" e representações apelativas sobre um "Estado ausente" que, erroneamente, não havia trabalhado para fornecer meios para que aquela riqueza fosse explorada como deveria. Nas entrelinhas, vemos surgir a "Amazônia" (OLIVEIRA, 2008, 2016) como um território pouco ocupado, atrasado e à espera de intervenções "racionais" que pudessem retirá-lo da inércia em que se encontrava. A população local, "os caboclos perdidos" que a habitavam, não poderia conduzir esse processo sem a participação de um herói civilizador: os "bandeirantes contemporâneos". Nos termos da fala do Senador Roberto Freire, estes últimos apenas estariam aguardando o "Estado" fazer sua parte, fornecendo a estrutura logística necessária para que pudessem avançar até essa nova praça e ali "fincar sua bandeira".

No contexto da discussão, penso que a escolha do termo "caboclo" para fazer alusão à população local não é aleatória. Muitas vezes tratado como um referente pejorativo, o "caboclo" é um dos personagens do enredo do processo de mestiçagem (CASTRO, F. F., 2013; NOLETO, 2018) que, segundo o quadro interpretativo hegemônico ${ }^{18}$ bastante criticado, teria dado origem ao Brasil e à sua população. Ainda que caracterizado por uma certa polissemia, em sua definição mais comum, o "caboclo" seria um termo utilizado para assignar um grupo étnico-racial de definição imprecisa surgido do "cru-

\footnotetext{
18 Há uma vasta bibliografia relacionada à discussão sobre como a ideia de mestiçagem compõe o processo de invenção da identidade nacional brasileira. Para citar apenas algumas obras mais clássicas, destaco os trabalhos de Gilberto Freyre (1981), Sergio Buarque de Holanda (1989) e Darcy Ribeiro (1995).
} 
zamento da 'raça branca' com a 'raça índia"', sendo, portanto, um vocábulo que ecoa a violência do processo colonial na região (CASTRO, F. F., 2013, p.432). Tratada como uma "identidade denegada" pelas populações amazônicas (CASTRO, F. F., 2013), a figura do "caboclo" consiste em uma classificação carregada de estigmas produzida no bojo das representações racistas mobilizadas para justificar "missões civilizatórias" no contexto do empreendimento colonial (OLIVEIRA, 2014). Através da fala do Senador Roberto Feire, vemos assim como a categoria ressoa uma leitura racializada que inferioriza as capacidades da população da região a título de legitimar intervenções estatais que poderiam levar o "desenvolvimento" e a "civilização" e garantir que esse povo não mais fosse um povo de "perdidos".

Por meio de formulações que espelham de maneira evidente elementos caros ao discurso colonial vemos como a "Amazônia" segue sendo projetada como um "espaço anacrônico", para onde se deslocar em busca de fincar "novas bandeiras" representaria tanto um trânsito no espaço como um recuo no tempo (MCCLINTOCK, 2010; NOLETO, 2018) ${ }^{19}$. A análise conjunta das representações empregadas para fundamentar o projeto de criação do estado do Tapajós ao longo do tempo nos permite visualizar como parece pairar sobre a "Amazônia" um enredo que nega à região um lugar na contemporaneidade, na medida em que as expectativas que provoca concomitantemente associam esse espaço ao atraso do passado ou a um futuro que chegará pelas mãos de outros. Nesse quadro, penso que a recorrência de representações binárias hierárquicas, a retomada da retórica do heroísmo civilizador e o uso da categoria "caboclo" para fazer referência à população local compõem uma linguagem de gestão marcada pela durabilidade do "legado colonial" e pela violência simbólica a ele associado.

\section{CONSIDERAÇÕES FINAIS}

A imagem de um país formado por "ilhas" e a retórica da integração necessária atravessam de maneira estrutural o processo de formação de Estado no Brasil, pautando inúmeras ações voltadas à colonização e administração

\footnotetext{
19 A partir da análise de representações em torno da cidade de Belém, Noleto (2018) apresenta uma reflexão similar que inspirou imensamente a discussão apresentada nessa seção.
} 
do território nacional ao longo do tempo (CARVALHO, 1988; MATTOS, 1990; VIDAL E SOUZA, 2015). Nesse quadro, a "Amazônia" tem sido produzida como a "última fronteira" a ser conquistada (VELHO, 2009; BECKER, 2010; OLIVEIRA, 2016). Na medida em que discursos sobre a necessidade dos projetos de reconfiguração territorial da Amazônia brasileira continuamente estiveram associados a discursos sobre a necessidade da integração nacional, penso que as propostas e os debates provocados em torno da realização do plebiscito no Pará em 2011 podem ser lidos como uma atualização de debates clássicos sobre a relação entre as "partes" da Nação.

Durante a pesquisa sobre a disputa em torno da criação do estado do Tapajós observei que os projetos de criação de novas unidades federativas na Amazônia Brasileira constituíam casos etnográficos instigantes para refletir sobre certas idealizações e imaginários correntes associados tanto ao "O Estado" (ABRAMS, 1988; MITCHEL, 2006; SOUZA LIMA, 2012) quanto à "Amazônia”. Ao longo das articulações realizadas no Congresso, o acionamento de uma determinada "imagem" da Amazônia (OLIVEIRA, 2008, 2016) - uma imensidão geográfica desocupada e atrasada que necessita da intervenção de "bandeirantes do futuro" para ser efetivamente "integrada" ao Brasil - revela a atualidade de processos de significação de longo de prazo (GEERTZ, 1991) que se traduzem em uma "gestão colonial" (SOUZA LIMA, 2007) desse espaço, deixando em evidência que a disputa em torno da criação do Estado do Tapajós não está desconectada de uma ordem simbólica particular, a qual historicamente tem sido acionada para justificar intervenções estatais na região.

Buscando evidenciar a forma como esses imaginários se desdobram em projetos e intervenções concretas na vida das populações que habitam a região, chamei a atenção para a sobreposição existente entre o projeto de criação do estado do Tapajós e o asfaltamento da rodovia Santarém-Cuiabá, a "rodovia da soja". Nesse ponto me parece importante sublinhar como as formulações em torno da "presença do Estado" na "Amazônia" esboçadas nos relatórios e nos debates descritos deixaram evidente que o projeto de criação do Tapajós, desde sua origem institucional, esteve entrelaçado a interesses e valores associados a setores do agronegócio nacional (DUTRA, 1999; BEMERGUY, 2017). Seguindo Oliveira (2016), penso que as continuidades destacadas ao analisarmos as materialidades e os discursos que buscavam legitimar os projetos de reconfiguração territorial da Amazônia e garantir a 
aprovação do projeto de convocação do plebiscito para criação do Estado do Tapajós "assumem o caráter de verdadeiro modelo de explicitação do destino econômico e social" pensado para a região. Nesse quadro, penso que os imaginários de longo prazo sobre a localidade, aliados à força política da bancada ruralista no Congresso Nacional, foram fundamentais para que o projeto fosse lido como algo que "interessava ao Brasil" (BEMERGUY, 2017) e para que alcançasse os votos que garantiram a realização da consulta.

Nesse ponto, me parece importante mencionar que a resposta negativa à criação dos novos Estados na Amazônia em 2011 não necessariamente indica o insucesso das representações acionadas ao longo das articulações no Congresso, muito menos um desejo da população consultada em repudiá-las por completo. Pesquisando sobre a mobilização em torno da criação do estado do Tapajós pude observar com muita transparência como a dimensão sedutora da promessa do progresso e do desenvolvimento ressoava entre os mais distintos personagens favoráveis à "causa”, mesmo entre setores mais críticos. Também é interessante destacar que, apesar da derrota em nível institucional, o voto "Sim" teve uma vitória esmagadora na região que corresponderia ao novo Estado. Esse apoio maciço, por sua vez, não representa um alinhamento transversal dos votantes e militantes do "Sim" ao Tapajós aos ideários que compõem o quadro do que descrevi como uma gestão colonial da Amazônia. Pelo contrário. Muitas das justificações com que me deparei foram apresentadas como um basta a essa dinâmica de exploração e como uma resposta à forma como entendiam que a região (Tapajós e Amazônia) era tratada pelos "Centros" a que estava subordinada como "periferia": Belém e o Brasil.

Essas elaborações críticas e dissonantes dos ideários que circundavam a proposta no espaço do Congresso Nacional também não devem ser interpretadas como uma negação completa do quadro simbólico hegemônico pensado para a gestão colonial da região. As linguagens da mobilização em torno da criação do Estado do Tapajós me conduziram a análise de diferentes "Sim" e me permitiram observar como um anseio coletivo pode crescer em meio a expectativas contraditórias. Neste artigo privilegiei a descrição da articulação do Sim ao projeto no espaço do Congresso Nacional, buscando destacar como as linguagens e materialidades da política caracterizam densos "textos culturais" (SHORE, WRIGHT, 1997). Nesse exercício etnográfico "para cima", (NADER, 1972) preferi demonstrar como uma análise da poética do 
poder - das ideias, mitos e valores particulares atualizados através da ação política (GEERTZ, 1991) - pode conduzir a reflexões sobre práticas conceituais duráveis mobilizadas para (re)afirmar a necessidade urgente de desenvolver e civilizar certos territórios no contexto de Estados-Nacionais forjados no bojo da experiência colonial. Os projetos de criação de novos Estados na Amazônia nos incitam a refletir sobre os efeitos dessa durabilidade, forçando-nos a enfrentar uma reflexão sobre o consenso produzido em meio à controvérsia e sobre o apelo popular alcançado por projetos estatais que ressoam a linguagem de projetos civilizatórios.

\section{REFERÊNCIAS BIBLIOGRÁFICAS}

1. ABRAMS, Philip. Notes on the Difficulty of Studying the State (1977). Journal of historical sociology, v. 1, n. 1, p. 58-89, 1988.

2. AGÊNCIA SENADO. Substitutivo. [201-] Disponível em: https://www12.senado. leg.br/noticias/glossario-legislativo/substitutivo. Acesso em: 27 ago. 2019.

3. ALARCON, Daniela Fernandes; GUERRERO, Natalia Ribas; TORRES, Maurício. Saída pelo norte: a articulação de projetos de infraestrutura e rotas logísticas na bacia do Tapajós. In: ALARCON, Daniela Fernandes; MILLIKAN, Brent; TORRES, Maurício (Org.). Ocekadi: hidrelétricas, conflitos socioambientais e resistência na Bacia do Tapajós. Brasília, DF: Internacional Rivers Brasil; Santarém, PA: Programa de Antropologia e Arqueologia da Universidade Federal do Oeste do Pará, 2016.

4. BECKER, Bertha. Revisão das políticas de ocupação da Amazônia: é possível identificar modelos para projetar cenários? Parcerias estratégicas, v. 6, nº 12, p. 135-159, 2010.

5. BEMERGUY, Telma de Sousa. Criando Estado, fazendo região: gramáticas em disputa na invenção do Estado do Tapajós. 2017. Dissertação (Mestrado) Universidade Federal do Rio de Janeiro, Rio de Janeiro, 2017.

6. BERNARDES, Júlia Adão Bernardes; FREIRE FILHO, Osni de Luna (Org.). Geografias da soja: BR-163, fronteiras em mutação. Rio de Janeiro: Arquimedes Edições, 2010.

7. BEZERRA, Marcos Otávio. Em nome das "bases": política, favor e dependência pessoal. Rio de Janeiro: Relume-Dumará/Núcleo de Antropologia da Política, 1999.

8. BOLTANSKI, Luc. El amor y la justicia como competencias: tres ensaios da sociologia da acción. Paris: Editión Métailié, 1990. 
9. BOURDIEU, Pierre. A identidade e a representação: elementos para uma reflexão crítica sobre a ideia de região. In: O poder simbólico. Rio de Janeiro: Bertrand Brasil, 1989.

10. BRASIL. Câmara dos Deputados. Substitutivo da Câmara dos Deputados ao Projeto de Decreto Legislativo no ${ }^{\circ}$, de 1999. Convoca plebiscito sobre a criação do Estado do Tapajós. Relator: Vital do Rego, 1999. [1999a]. Disponível em: https://www25.senado.leg.br/web/atividade/materias/-/materia/100176? $=\mathrm{t} \quad$. Acesso em: 10 ago. 2016.

11. BRASIL. Comissão de Estudos Territoriais. Relatório no 01, de 1990: sobre o território nacional e anteprojetos relativos a novas unidades territoriais, notadamente na Amazônia Legal e em áreas pendentes de solução. Relator: Deputado Gabriel Guerreiro. [1990].

12. BRASIL. [Constituição (1988)]. Constituição da República Federativa do Brasil de 1988. Brasília, DF: Presidência da República, [2016]. Disponível em: http:// www.planalto.gov.br/ccivil_03/constituicao/constituicaocompilado.htm. Acesso em: 10 ago. 2016.

13. BRASIL. Lei $\mathbf{n}^{\circ} \mathbf{9 . 7 0 9}$, de 18 de novembro de 1998. Regulamenta a execução do disposto nos incisos I, II e III do art. 14 da Constituição Federal. Disponível em: http://www.planalto.gov.br/ccivil_03/leis/l9709.htm. Acesso em: 18 ago. 2019.

14. BRASIL. Senado Federal. Diário do Senado Federal, Brasília, DF, n. 186, p. 23060-23062, 24 de novembro de 2000. Disponível em: https://legis.senado.leg. br/diarios/BuscaDiario?codDiario=3995\#diario. Acesso em: 21 ago. 2019.

15. BRASIL. Senado Federal. Projeto de decreto legislativo no 19, de 1999. Convoca plebiscito sobre a criação do estado do Tapajós. Autoria: Senador Mozarildo Cavalcanti. Relator: Romeu Tuma, 02 de março de 1999. [199b] Disponível em: https://www25.senado.leg.br/web/atividade/materias/-/materia/608. Acesso em: 10 ago. 2016.

16. BRASIL. Senado Federal. Resolução no 93, de 1970. Dá nova redação ao Regimento Interno do Senado Federal. Brasília/DF: Senado Federal, 1970. Disponível em: https:/www25.senado.leg.br/web/atividade/regimento-interno. Acesso em: 18 ago. 2019.

17. CARVALHO, José Murilo de. Federalismo e centralização no Império brasileiro: história e argumento. In: CARVALHO, José Murilo de. Pontos e bordados: escritos de história e política. Belo Horizonte: Ed. UFMG, 1998.

18. CASTILHO, Sergio Rodrigues; SOUZA LIMA, Antônio Carlos de; TEIXEIRA, Carla Costa. Etnografando burocratas, elites e corporações: a pesquisa entre estratos sociais hierarquicamente superiores em sociedades contemporâneas. CASTILHO, Sergio Rodrigues; SOUZA LIMA, Antônio Carlos de; TEIXEIRA, Carla Costa (Ed.). Antropologia das práticas de poder: reflexões etnográficas entre burocratas, elites e corporações. Rio de Janeiro: Contra Capa, 2014. 
19. CASTRO, Edna. Sociedade, território e conflitos: BR 163 em questão. Belém: NAEA/UFPA, 2008.

20. CASTRO, Maria da Conceição Araujo. Mobilização do trabalho na Amazônia. O oeste do Pará entre grilos, latifúndios, cobiças e tensões. 2008. Tese (Doutorado em Geografia) - Faculdade de Filosofia Letras e Ciências Humanas, Universidade de São Paulo, São Paulo, 2008.

21. CASTRO, Fabio Fonseca de. A identidade denegada. Discutindo as representações e a autorrepresentação dos caboclos da Amazônia. Revista de Antropologia, São Paulo, v.56, n. 2, p. 431-475, 2013.

22. COIMBRA, Hilário. Estado do Tapajós: uma opção para o desenvolvimento da Amazônia. Brasília: Câmara dos Deputados, 1993.

23. COIMBRA, Hilário. Estudo de viabilidade econômica do Estado do Tapajós. Brasília: Câmara dos Deputados, 1997.

24. COSTA, Sandra Helena Gonçalves. A questão agrária no Brasil e a bancada ruralista no Congresso Nacional. 2012. Tese (Doutorado em Geografia) Faculdade de Filosofia Letras e Ciências Humanas, Universidade de São Paulo, São Paulo, 2012.

25. COSTA, Célio; PACHECO, Peterson. Fundamentos para a criação do Estado do Tapajós: efetivando a presença do Estado na Amazônia Brasileira. Brasília, 2011.

26. DUTRA, Manuel. O Pará dividido: discurso e construção do Estado do Tapajós. Belém: UFPA/NAEA, 1999.

27. ESCOBAR, Arturo. Mundos y conocimientos de otro modo: el programa de investigación modernidad/colonialidad latinoamericano. Tabula Rasa, Bogotá, n. 1, p.58-86, 2003.

28. FRANCISCO Mozarildo de Melo Cavalcanti. In: DICIONÁRIO HistóricoBiográfico Brasileiro. Rio de Janeiro: FGV, [2009]. Disponível em: http://www. fgv.br/cpdoc/acervo/dicionarios/verbete-biografico/francisco-mozarildo-demelo-cavalcanti. Acesso em: 12 dez. 2016.

29. FREYRE, Gilberto. Casa Grande \& Senzala: formação da família brasileira sob o regime da economia patriarcal. Rio de Janeiro: José Olympio, 1981 [1933].

30. GEERTZ, Cfifford. Negara: O Estado teatro no século XIX. Lisboa: Difel, 1991.

31. HOLANDA, Sérgio Buarque de. Raízes do Brasil. Rio de Janeiro: José Olympio, 1989.

32. LISBOA, Flávia Marinho. Análise discursiva das propagandas eleitorais radiofônicas do plebiscito para a divisão do Pará. 2014. Dissertação (Mestrado)

- Universidade Federal do Sul e Sudeste do Pará, Marabá, 2014.

33. MARTINS, Herbert Toledo. A fragmentação do território nacional: a criação de novos estados no Brasil (1823-1988). 2003. Tese (Doutorado) - Instituto 
de Filosofia e Ciências Sociais, Universidade Federal do Rio de Janeiro, Rio de Janeiro, 2003.

34. MATTOS, Ilmar Rohloff de. O tempo saquarema: a formação do Estado Imperial. 2.ed. São Paulo: Hucitec, 1990.

35. MCCLINTOCK, Anne. Couro imperial: raça, gênero e sexualidade no embate colonial. Campinas: Unicamp, 2010 [1995].

36. MIGNOLO, Walter. El pensamiento descolonial: desprendimento y apertura. Un manifiesto. In: CASTRO-GÓMEZ, Santiago; GROSFONGUEL R. (Org.), El giro descolonial. Reflexiones para uma diversidad epistémica más allá del capitalismo global. Bogotá: Siglo del Hombre Editores, 2007.

37. MITCHEL, Timothy. Society, Economy and the State Effect. In: SHARMA, Aradhana; GUPTA, Akhil (Ed.). The Anthropology of the State: A Reader. Oxford: Blackwell Publishing, 2006.

38. NADER, Laura. Up the anthropologist: perspectives gained from studying up. Berkeley: University of California, 1972.

39. NOLETO, Rafael da Silva. Cor de jambo e outros matizes amazônicos: sobre a abolição da mulata e o advento da morena cheirosa nas festas juninas de Belém. Mana, Rio de Janeiro, v. 24, n. 2, p. 132-173, 2018.

40. PRÓ-OESTE (Movimento); PRÓ-CRIAÇÃO DO ESTADO DO TAPAJÓS (Movimento). Estudo de viabilidade econômica do Estado do Tapajós. Santarém: Tiagão, 1996.

41. OLIVEIRA, João Pacheco de. A fronteira e seus cenários: narrativas e imagens sobre a Amazônia. In: NORONHA, Nelson de Matos; ATHIAS, Renato (Org.). Ciência e Saberes na Amazônia: indivíduos, coletividades, gênero e etnias. Recife: Editora Universitária UFPE, 2008.

42. OLIVEIRA, João Pacheco de. Narrativas e imagens sobre povos indígenas e Amazônia: uma perspectiva processual da fronteira. In: OLIVEIRA, João Pacheco de. O Nascimento do Brasil e outros ensaios: "pacificação", regime tutelar e formação de alteridades. Rio de Janeiro: Contracapa, 2016.

43. OLIVEIRA, João Pacheco de. Pacificação e tutela militar na gestão de populações e territórios. Mana, Rio de Janeiro, v. 20, n. 1, p. 125-161, 2014.

44. OLIVEN, Ruben. A parte e o todo: a diversidade cultural no Brasil-Nação. Rio de Janeiro: Editora Vozes, 2011.

45. QUIJANO, Anibal. Coloniality of power and Eurocentrism in Latin America. International Sociology, v.15, n. 2, p.215-232, 2000.

46. RIBEIRO, Darcy. O povo brasileiro: a formação e o sentido do Brasil. São Paulo: Global Editora e Distribuidora Ltda, 2015. 
47. SAID, Edward. Orientalismo: o Oriente como invenção do Ocidente. São Paulo: Companhia das Letras, 1990.

48. SENADO FEDERAL (Brasil). Mozarildo Cavalcanti - RR. In: SENADO FEDERAL (Brasil). Senadores. [Brasília, DF]: Senado Federal, [2015]. Disponível em: https://www25.senado.leg.br/web/senadores/senador/-/perfil/952 . Acesso em: 12 dez. 2016.

49. SENADO FEDERAL (Brasil). Roberto Freire - PE. In: SENADO FEDERAL (Brasil). Senadores. [Brasília, DF]: Senado Federal, [2003]. Disponível em: https://www25.senado.leg.br/web/senadores/senador/-/perfil/71. Acesso em: 07 jan. 2018.

50. SHARMA, Aradhana; GUPTA, Akhil. Introduction: Rethinking Theories of State in an Age of Globalization. In: SHARMA, Aradhana; GUPTA, Akhil. (Ed.). The Anthropology of the State: A Reader. Oxford: Blackwell Publishing, 2006. p. 1-41.

51. SHORE, Chris; WRIGHT, Susan. Policy: a new field of anthropology. In: SHORE, Chris; WRIGHT, Susan. (Ed.). Anthropology of policy. Critical perspectives on governance and power. London and New York: Routledge, 1997. p. 3-39.

52. SOUZA LIMA, Antônio Carlos de. Apresentação. Dossiê Fazendo Estado. O estudo antropológico das ações governamentais como parte dos processos de formação estatal. Revista de Antropologia, São Paulo, v. 55, p. 559-564, 2012.

53. SOUZA LIMA, Antônio Carlos de. Gestar e gerir: estudos para uma antropologia da administração pública no Brasil. Relume Dumará, 2002a.

54. SOUZA LIMA, Antônio Carlos de. Tradições de conhecimento na gestão colonial da desigualdade: reflexões a partir da administração indigenista no Brasil. Trânsitos coloniais: diálogos críticos luso-brasileiros. Lisboa: Imprensa de Ciências Sociais, 2002b.

55. TORRES, Maurício (Org.). Amazônia revelada: os descaminhos ao longo da BR163. Brasília: CNPQ, 2005.

56. VELHO, Otávio Guilherme. Capitalismo autoritário e campesinato. Rio de Janeiro: Centro Edelstein de Pesquisas Sociais, 2009.

57. VIDAL E SOUZA, Candice. A pátria geográfica: sertão e litoral no pensamento social brasileiro. Goiânia: Editora UFG, 2015.

Recebido em 17 de janeiro de 2019

Avaliador A: 27 de fevereiro de 2019

Avaliador B: 05 de março de 2019

Aceito em 05 de março de 2019 